\title{
A qualitative assessment of breast cancer awareness in an urban Indian city
}

\begin{abstract}
Objective: To assess the awareness of breast cancer and associated risk factors among educated women from an urban population in Mumbai, India.

Materials and methods: A self-directed questionnaire-based survey was used. The questions were based on, life style habits, medical history, menstrual and contraceptive history, risk factor awareness and screening for breast cancer.

Results: Nine hundred and fifty women were invited for the survey, 763 responded. The mean age of the cohort was 31years (range 18-60). Knowledge about screening and breast self-examination (BSE) was evident in $682(89.38 \%)$ of respondents. Furthermore, 334 (44\%) of respondents were previously informed about BSE), of which 148 (19\%) regularly performed a BSE. Awareness of breast cancer screening with mammography was reported by $310(41 \%)$ subjects. Forty-two women $(6 \%)$ had undergone mammography screening, with increased incidence among homemakers compared to professionals and students.

Conclusion: The current study highlights the need for outreach programs to educate women about breast cancer and inform them about prognosis and self-evaluation methods for diagnosing the disease. In addition strategies to improve the compliance of breast screening programs are needed.
\end{abstract}

Keywords: breast cancer, awareness, response, education, mammogram, breast selfexamination
Volume 6 Issue 4 - 2016

Anupma Harshal,' Maryam Alfa-Wali, ${ }^{2}$ Jadhav Deepika,' Jhaveri Prachi,' Sanchita Ahluwalia,' Shailaja Rane,' Anand Sharma ${ }^{3}$

'Department of Biotechnology, Kishinchand Chellaram College, India

${ }^{2}$ Imperial College, Department of Surgery and Cancer, UK ${ }^{3}$ Department of Oncology, Mount Vernon Hospital, UK

Correspondence: Anand Sharma, MBBS, M D, MRCP UK, MRCP Medical Oncology Medical Oncologist, Mount Vernon Hospital, Northwood, UK, HA6 2RN, Tel 7708540238, Email drandy2003@gmail.com

Received: October 22, 2016 | Published: December 21, 2016

\section{Introduction}

Breast cancer is one of the most common malignancies found in women and is associated with increased mortality in advanced disease. ${ }^{1}$ The incidence of breast cancer has increased over the past $30 y e a r s$ due to a variety of factors from improved screening methods, longevity, and exposure to carcinogens to changes in lifestyle. ${ }^{2}$ However, the mortality rate is decreasing, reflecting the benefits of early detection, screening and improvements in treatment. ${ }^{3}$ Breast cancer is the most prevalent malignant disease among women in India with approximately 100,000 thought to be diagnosed by the end of $2015 .{ }^{4}$ In 2005, 4500 new cases of breast cancer were reported in Mumbai, accounting for $27.5 \%$ of the total number of new cancer cases seen in India, with an estimated 5-year survival of $60 \% .^{5}$ The increasing incidence of breast cancer is thought to be due to rapid changes in lifestyle and industrialisation. The changing risk profile among younger generations combined with westernisation of lifestyle, which includes late age of first birth, and lower parity.

Awareness, education, timely screening, prevention and early treatment have resulted in the significant reductions in mortality and improved well being of women with breast cancer. Randomised controlled clinical trials and meta-analyses have consistently demonstrated that biennial screening mammography results in a projected $17 \%$ reduction in mortality compared to no screening. ${ }^{8,9}$ There have been significant improvements in patient outcomes as a result of continually evolving and improving standards of care, increased community awareness and new treatment modalities for breast cancer. ${ }^{10}$ The aim of this study was to evaluate the level of breast cancer awareness and its screening measures (breast self examination (BSE), breast screening, mammography) amongst women in an urban city.

\section{Methods}

A questionnaire was used to assess the knowledge of women from students to working professionals living in Mumbai, India. The questionnaire was developed in collaboration with oncologists, epidemiologists, health care professionals and psychologists. Nine hundred and fifty questionnaires were sent to the selected study areas. The Kishinchand Chellaram College Ethics Committee approved the study and all participants gave written informed consent. The questionnaire included demographic data as well as specific questions associated with breast cancer risk factors. Questions assessed (1) general awareness about breast cancer, (2) diet and lifestyle habits such as alcohol, tobacco consumption and smoking, (3) significant medical history, (4) menstrual history and (5) information about screening, breast self-examination, breast screening, mammography. The data was analysed using standard statistical tools.

\section{Results}

\section{Study population and socio-demographic characteristics}

Out of 950 questionnaires distributed, the response rate was $80 \%$ $(\mathrm{n}=763)$. Respondent demographics are presented in Table 1. The age range was between 18 and 60years with a mean age of 29 . Of the 763 subjects, $249(33 \%)$ were married and 501 (67\%) were single (including divorced and widowed).

\section{Knowledge and awareness about breast cancer}

Respondents were asked about their knowledge of breast cancer as a disease and the associated symptoms. Eighty nine per cent $(n=682)$ of the participants were generally aware of breast cancer as a disease, 
whereas $10 \%(\mathrm{n}=81)$ were unfamiliar with the subject. One hundred and two respondents were aware that breast cancer could affect both sexes, while $86 \%(n=658)$ reported that breast cancer only affected women. One hundred and nine (14\%) had previously discussed breast cancer with their family physician at some point in their lifetime. Interestingly, 83 participants thought breast cancer was infectious and only $44 \%(n=338)$ understood breast cancer as a hereditary disease.

Table I Socio-demographic characteristics of the study population

\begin{tabular}{|c|c|c|c|}
\hline & & Number & $\%$ \\
\hline \multirow[t]{4}{*}{ Age group } & $18-30$ & 522 & 68.41 \\
\hline & $31-45$ & 150 & 19.66 \\
\hline & $46-60$ & 67 & 8.78 \\
\hline & Not mentioned & 24 & 3.15 \\
\hline \multirow[t]{5}{*}{ Marital status } & Single & 497 & 65.14 \\
\hline & Married & 249 & 32.63 \\
\hline & Divorced & 3 & 0.39 \\
\hline & Widowed & I & 0.13 \\
\hline & Not mentioned & 13 & 1.7 \\
\hline \multirow[t]{5}{*}{ Highest Level of Education } & University & 119 & 15.59 \\
\hline & College & 430 & 56.36 \\
\hline & Schooling & 30 & 3.93 \\
\hline & No formal education & 40 & 5.24 \\
\hline & Not mentioned & 144 & 18.87 \\
\hline \multirow[t]{4}{*}{ Occupation } & Teacher & 34 & 4.45 \\
\hline & Self-employed & 163 & 21.36 \\
\hline & Homemaker & 160 & 20.96 \\
\hline & Student & 406 & 53.21 \\
\hline \multirow[t]{5}{*}{ Menstrual status } & Premenopausal & 53 & 6.94 \\
\hline & Post-menopausal & 65 & 8.51 \\
\hline & Peri-menopausal & 643 & 84.27 \\
\hline & Undergone hysterectomy & 2 & 0.26 \\
\hline & \multicolumn{3}{|c|}{ Total Number of respondents: 763} \\
\hline
\end{tabular}

Table 2 Prevalent knowledge/myths of breast cancer among respondents

\begin{tabular}{lllll}
\hline & Yes & (\%) & No & (\%) \\
\hline Awareness of breast cancer as a disease \& its symptoms & 682 & 89.38 & 81 & 10.61 \\
Discussed breast cancer with professionals & 109 & 14.28 & 654 & 85.71 \\
Breast cancer is infectious & 83 & 10.87 & 680 & 89.12 \\
Breast cancer is hereditary & 338 & 44.29 & 425 & 55.7 \\
\hline
\end{tabular}

Awareness of breast cancer as a disease was higher among students $(\mathrm{n}=391)$ compared to other groups (Table 2). The most widely endorsed barrier could be hesitation, lack of knowledge, emotional barrier or inability to make an appointment with the physician without any symptoms. The understanding about mammography was reported by 310 women and was higher in professionals and self-employed participants. Among individuals aware of mammography, only six per cent had undergone this procedure. Similarly, 334 (44\%) participants were aware of BSE, but only $148(19 \%)$ had actually performed a BSE Table 3.

Table 3 Subgroup analysis of general awareness of breast cancer as a disease

\begin{tabular}{lllll}
\hline & Yes & $\%$ & No & $\%$ \\
\hline Teacher & 33 & 4.32 & $\mathrm{I}$ & 0.13 \\
Self-employed & 150 & 19.65 & 13 & 1.7 \\
Homemaker & 108 & 14.15 & 52 & 6.94 \\
Student & 391 & 51.24 & 15 & 1.96 \\
Total & 682 & 89.36 & 81 & 10.73 \\
\hline
\end{tabular}

Table 4 Dietary and lifestyle habits

\begin{tabular}{lll}
\hline Lifestyle & Respondents & $\%$ \\
\hline Sedentary & 68 & 8.91 \\
Moderate & 611 & 80.08 \\
Heavy & 43 & 5.64 \\
Not mentioned & 41 & 5.37 \\
Total & 763 & \\
\hline
\end{tabular}

\section{Dietary and lifestyle habits}

According to our findings, 348 (46\%) subjects were aware of foods that can reduce the risk of breast cancer (Table 4). Nine per cent $(n=68)$ had a sedentary lifestyle compared with $80 \%(n=611)$ that followed a moderate lifestyle. Cigarette smoking and alcohol consumption was higher among professionals compared to housewives and students. Tobacco-related product consumption (betel nut, betel leaves, paan masala and masheri) was significantly higher among homemakers (12\%) compared to self-employed individuals (4\%) and students (1\%) (Table 5). 


\section{Family history of cancer and exposure to radiation}

Of the 763 subjects of our study, 166 respondents (22\%) had a family history of cancer, with 51 (31\%) specifically of breast cancer. Table 6 shows that of subjects with a family history of cancer, 72 $(43 \%)$ had undergone breast cancer screening.Furthermore, 337 $(44.16 \%)$ respondents had been exposed to some form of radiation in their lifetime e.g. X-rays, Computed tomography.

\section{Self-reported breast-related symptoms}

Ten women had noticed swelling of their breasts on selfexamination, whereas 29 had skin irritation and 20 had experienced nipple pain (Table 7). Ten subjects had reported a lump in the underarm area, as well as unusual nipple discharge.

Table 5 Other habits

\begin{tabular}{llllllllll}
\hline Habits & Total & $\begin{array}{l}\text { Cigarettl } \\
\text { Alcohol }\end{array}$ & $\%$ & $\begin{array}{l}\text { Betel Nuts/ Betel Leaves/ Paan } \\
\text { Masala* }\end{array}$ & $\%$ & $\begin{array}{l}\text { More than One } \\
\text { Habit }\end{array}$ & $\%$ & Nil & $\%$ \\
\hline $\begin{array}{l}\text { Teacher } \\
\text { Self- }\end{array}$ & 34 & 2 & 5.88 & - & - & - & - & 32 & 94.11 \\
employed & 163 & 4 & 2.45 & 6 & 3.68 & - & - & 153 & 93.86 \\
Homemaker & 160 & 1 & 0.625 & 19 & 11.87 & 3 & 1.87 & 137 & 85.62 \\
Student & 406 & 10 & 2.46 & 5 & 1.23 & 6 & 1.47 & 385 & 94.82 \\
Total & 763 & 17 & 2.22 & 30 & 3.93 & 9 & 1.17 & 707 & 92.66 \\
\hline
\end{tabular}

*In South Asia, paan masala is the practice of chewing pieces of areca nut with lime folded into a betel leaf.

Table 6 Family history of cancer and exposure to radiation

\begin{tabular}{|c|c|c|c|c|c|c|c|c|c|}
\hline \multirow{2}{*}{$\begin{array}{l}\text { Subgroup } \\
\text { Analysis }\end{array}$} & \multicolumn{3}{|c|}{ Undergone Mammography } & \multicolumn{3}{|l|}{ BSE } & \multicolumn{3}{|c|}{ Undergone PAP Smear } \\
\hline & $\begin{array}{l}\text { Family History } \\
\text { (h/o) }\end{array}$ & $\begin{array}{l}\text { No Family } \\
\text { h/o }\end{array}$ & Total & $\begin{array}{l}\text { Family } \\
\text { h/o }\end{array}$ & $\begin{array}{l}\text { No Family } \\
\text { h/o }\end{array}$ & Total & $\begin{array}{l}\text { Family } \\
\text { h/o }\end{array}$ & $\begin{array}{l}\text { No Family } \\
\text { h/o }\end{array}$ & Total \\
\hline \multirow{3}{*}{$\begin{array}{l}\text { Teacher } \\
\text { Self- } \\
\text { employed } \\
\text { Homemaker }\end{array}$} & 3 & 2 & I & 16 & 7 & 6 & 8 & 4 & 4 \\
\hline & 15 & 7 & 8 & 51 & 13 & 38 & 20 & 7 & 13 \\
\hline & 20 & 8 & 7 & 30 & 6 & 24 & 11 & 5 & 6 \\
\hline Student & 4 & 1 & 3 & 51 & 12 & 39 & 2 & - & 2 \\
\hline Total & 42 & & & 148 & & & 41 & & \\
\hline
\end{tabular}

Table 7 Self-reported breast-related symptoms

\begin{tabular}{lll}
\hline Respondents with any of the Following Symptoms & Number & $\%$ \\
\hline Swelling & 10 & 1.3 \\
Skin irritation & 29 & 4 \\
Nipple pain & 20 & 2.6 \\
Redness & 2 & 0.3 \\
Nipple discharge other than breast milk & 1 & 0.14 \\
Lump in the underarm area & 10 & 1.4 \\
Nipple retraction & 2 & 0.3 \\
Total with symptoms & 74 & 9.7 \\
None & 689 & 90.3 \\
Total & 763 & \\
\hline
\end{tabular}

\section{Discussion}

This is a survey-based study that evaluated the knowledge of breast cancer symptoms and risk factors in a female urban population in India. Assessment of participant knowledge about cancer indicated that there is considerable potential for improvement in breast cancer screening awareness. Increased awareness was more common in students compared to other members of the study population. Perhaps the use of social and mass media awareness about various lifethreatening diseases, such as breast cancer, are likely responsible for this observation. Additionally, understanding and knowledge about breast cancer appeared to be associated with level of formal education as well as interaction and information from family physicians,

With increasing evidence of the association between cancer and modifiable risk factors, such as obesity, hypertension, smoking, alcohol consumption, diabetes and dyslipidemia, it is imperative to increase public awareness of these factors and devise strategies to introduce early lifestyle changes on a global level. ${ }^{11-16}$ Smoking, alcohol use, as well as low fruit and vegetable intake, have been reported to be the leading risk factors for death from cancer worldwide. ${ }^{17,18}$

The rates of BSE vary in different countries, ranging rom up to $52 \%$ in India, 54\% in England and 55\% in Malaysia. ${ }^{19-21}$ The findings from our study are consistent with a previous study about breast cancer preventive measures (BSE \& BS), among South Asian communities in the UK. ${ }^{22}$ These are also evident in our study, in which a majority of subjects carry out BSE rather than undergoing mammography potentially as a result of fear of exposure to radiation. Yarbrough and Braden reported one of the barriers to screening behaviours included fear of results, treatment and the test itself. ${ }^{23}$ 
There are a number of limitations of the study. Firstly, all participants belonged to higher socio-economic background. Hence, our results may not be completely applicable to women of lower socioeconomic status. Secondly, individuals aged 60years or younger, were invited to participate in the study hence indicating a selection bias, as this may not be representative of the general population especially as breast cancer is proportionally higher in women over 60years. Third, participants included in the study were mostly educated women, and there could have been selection bias. It could be argued that the corresponding rates in less literate women would be assumed to be different than our group. We speculate that a less literate population would have inadequate access to health services due to lifestyle factors and cost considerations of private healthcare. Therefore, it is possible that findings may not apply to the entire Indian population.

However, with improved level of education and standard of living this may be a good qualitative assessment for future policy planning. In conclusion, measures to improve knowledge and awareness about breast cancer screening, early advice and involvement in healthcare programs may ultimately lead to increased rates of survival and, hence, reduced mortality from this life-threatening disease. The current study highlights the need to prioritise planning for cancer support services in a country, such as India, with diverse cultural and economic needs. Furthermore, it emphasises involvement of the healthcare system to actively increase awareness of breast cancer symptoms, services available, and screening or detection methods. An understanding of the heterogeneity in the socio-economic and cultural habits of women is essential in directing healthcare awareness.

Coming from a diverse ethnic and conservative/orthodox background, subjects may be embarrassed to talk to a healthcare professional about the symptoms due to lack of awareness. This may be attributed to education, participation in women development and awareness/outreach programs. Greater awareness among students is likely attributed to social media. Due to the structure of the healthcare system in Mumbai, accessibility to breast screening centers is limited, acting as an obstacle for early detection as there are very few healthcare centers that offer free screening facilities. Also, the services at these mammography clinics are only paid for directly by the patient or private insurers. Formal comparative statistics were not possible due to lack of stability in matching the large cohort with many variables. Breast cancer awareness helps women to acknowledgement the part they can play in being empowered to improve their health, not in terms of statistics used for mortality but on the qualitative effects of reductions in morbidity.

\section{Acknowledgments}

This work was supported by the Science Honours Program JIGYAASA (Innovative Practice-University Grants Commission) at Kishinchand Chellaram College, affiliated with the University of Mumbai, India. The authors would like to thank Dr. Shripad D Banavali (HOD Pediatric Oncology, Tata Memorial Hospital, Mumbai, India) for his valuable contribution to the study.

\section{Conflicts of interest}

Authors declare there are no conflicts of interest.

\section{References}

1. Siegel R, Naishadham D, Jemal A. Cancer statistic-2013. CA Cancer J Clin. 2013;63(1):11-30

2. van Gemert WA, Schuit AJ, van der Palen J, et al. Effect of weight loss, with or without exercise, on body composition and sex hormones in postmenopausal women: the SHAPE-2 trial. Breast Cancer Res. $2015 ; 17: 120$

3. Jonsson H, Nystrom L, Tornberg S, et al. Service screening with mammography of women aged 50-69 years in Sweden: effects on mortality from breast cancer. $J$ Med Screen. 2001;8(3):152-160.

4. Takiar R, Nadayil D, Nandakumar A. Projections of number of cancer cases in India (2010-2020) by cancer groups. Asian Pac J Cancer Prev. 2010;11(4):1045-1049.

5. Marimuthu P . Projection of cancer incidence in five cities and cancer mortality in India. Indian J Cancer. 2008;45(1):4-7.

6. Bagchi S. Breast cancer rises in India. CMAJ. 2008;179(1):27.

7. Key TJ, Schatzkin A, Willett WC, et al. Diet, nutrition and the prevention of cancer. Public Health Nutr. 2004;7(1A):187-200.

8. US Preventive Services Task Force. Screening for breast cancer: US Preventive Services Task Force recommendation statement. Ann Intern Med. 2009;151(10):716-726.

9. Musolino A, Michiara M, Conti GM, et al. Human epidermal growth factor receptor 2 status and interval breast cancer in a population-based cancer registry study. J Clin Oncol. 2012;30(19):2362-2368.

10. Yip $\mathrm{CH}$, Buccimazza I, Hartman $\mathrm{M}$, et al. Improving outcomes in breast cancer for low and middle income countries. World $J$ Surg. 2015;39(3):686-692.

11. Johnson KC, Hu J, Mao Y. Passive and active smoking and breast cancer risk in Canada, 1994-97. Cancer Causes Control. 2000;11(3):211-221.

12. Peacock SL, White E, Daling JR, et al. Relation between obesity and breast cancer in young women. Am J Epidemiol. 1999;149(4):339-346.

13. Gilliland FD, Li YF, Baumgartner K, et al. Physical activity and breast cancer risk in hispanic and non-hispanic white women. Am J Epidemiol. 2001;154(5):442-450.

14. Bowlin SJ, Leske MC, Varma A, et al. Breast cancer risk and alcohol consumption: results from a large case-control study. Int J Epidemiol. 1997;26(5):915-923.

15. Ferraroni M, Decarli A, Franceschi S, et al. Alcohol consumption and risk of breast cancer: a multicentre Italian case-control study. Eur $J$ Cancer. 1998;34(9):1403-1409.

16. Männistö S, Virtanen M, Kataja V, et al. Lifetime alcohol consumption and breast cancer: a case-control study in Finland. Public Health Nutr. 2000;3(1):11-18.

17. Braga $\mathrm{C}$, Negri E, Vecchia $\mathrm{C}$ La, et al. Cigarette smoking and the risk of breast cancer. Eur J Cancer Prev.5(3):159-164.

18. Gammon MD, Schoenberg JB, Teitelbaum SL, et al. Cigarette smoking and breast cancer risk among young women (United States). Cancer Causes Control. 1998;9(6):583-590.

19. Al-Dubai SA, Ganasegeran K, Alabsi AM, et al. Exploration of barriers to breast-self examination among urban women in Shah Alam, Malaysia: a cross sectional study. Asian Pac J Cancer Prev. 2012;13(4):1627-1632.

20. Gupta SK. Impact of a health education intervention program regarding breast self examination by women in a semi-urban area of Madhya Pradesh, India. Asian Pac J Cancer Prev. 2009;10(6):1113-1117.

21. Yadav P, Jaroli DP. Breast cancer: Awareness and risk factors in collegegoing younger age group women in Rajasthan. Asian Pac J Cancer Prev. 2010;11(2):319-322.

22. Karbani G1, Lim JN, Hewison J, et al. Culture, attitude and knowledge about breast cancer and preventive measures: a qualitative study of South Asian breast cancer patients in the UK. Asian Pac J Cancer Prev. 2011;12(6):1619-1626.

23. Yarbrough SS, Braden CJ. Utility of health belief model as a guide for explaining or predicting breast cancer screening behaviours. $J A d v$ Nurs.01;33(5):677-688. 